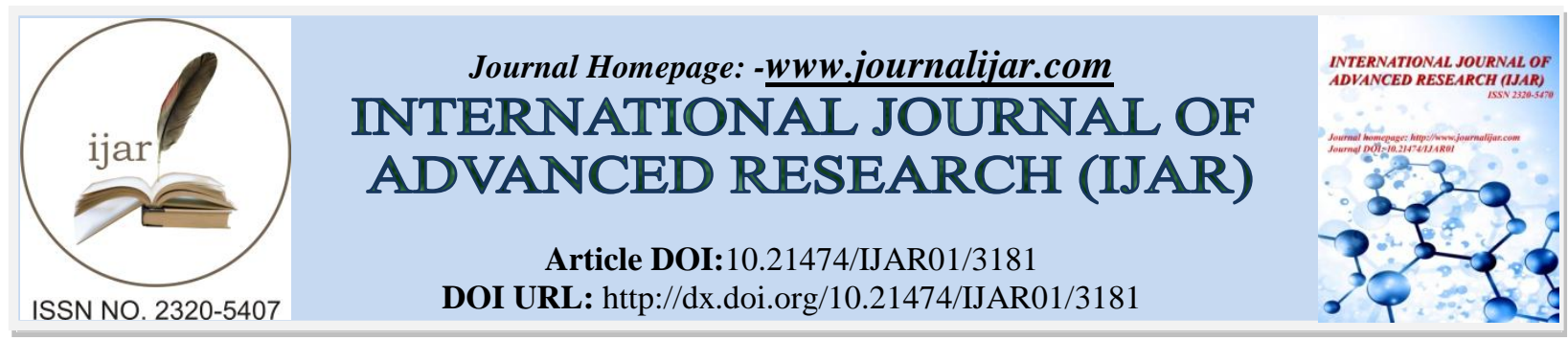

RESEARCH ARTICLE

\title{
THE GENETICS OF SYSTEMIC LUPUSERYTHEMATOSUSIN SAUDI ARABIA
}

\author{
Rami Nassir*. \\ Department of Pathology, School of Medicine, Umm Al-Qura University, Mecca, Saudi Arabia.
}

\section{Manuscript Info}

Manuscript History

Received: 16 December 2016

Final Accepted: 10 January 2017

Published: February 2017

Key words:-

Systemic Lupus Erythematosus, consanguinity, Genome Wide

Association Studies, exome sequencing.

\begin{abstract}
Systemic Lupus Erythematosus (SLE) is a complex multisystem autoimmune disorder. It is characterized by the production of autoantibodies that react against its own tissues, which may lead to immune-complex mediated end organ involvement. There are more than 30 genetic loci in different ethnic backgrounds that have been associated with the risk of developing this disease. The high level of consanguinityin the Saudi population is a risk factor for developing the disease. On the other hand, it provides an opportunity to identify the genetic variations that are associated with the disease. Applying Genome Wide Association Studies (GWAS) and exome sequencing would help to identify these variations. This review provides an opportunity to outline the genetics of Systemic Lupus Erythematosus in the Saudi population.
\end{abstract}

Copy Right, IJAR, 2017,. All rights reserved.

\section{Introduction:-}

Systemic Lupus Erythematosus (SLE) is a complex multisystem autoimmune disorder. It is characterized by the production of autoantibodies that react against its own tissues, which may lead to immune-complex mediated end organ involvement. SLE can affect almost any part of the body and it can range from mild to severe. The most common clinical features are kidney diseases, thrombotic problems and skin diseases. SLE is associated with wide range of autoantibodies, which could help in the diagnosis and monitoring the progress of the disease. The complexity of this autoimmune disease with the diverse clinical manifestations makes the progress of understanding the pathogenesis of SLE quite challenging. Despite these challenges, it has been reported that there are several factors that have roles in the development of SLE such as genetic susceptibility, gender, age, hormonal and environmental factors.(Hersh et al., 2016; O'Neill \& Cervera, 2010; Smith \& Gordon, 2010)

Based on many epidemiological studies, there are marked differences in the incidence of SLE, which mainly based on the features of the studied populations. (Pons-Estel, Alarcon, Scofield, Reinlib, \& Cooper, 2010) In Europe, it is estimated to be 2.2 cases per 100,000 per yearwhile in the US it is estimated to be 7.6 per 100,000 cases per year.(Lopez, Mozo, Gutierrez, \& Suarez, 2003)The worldwide prevalence ranges from 10 to 150 per 100,000 per year.(Cervera et al., 1999; Fessel, 1974)These variations are due to the difference in the ethnic groups, as it appears to be higher and more severe in the non-European ancestry.(Borchers, Naguwa, Shoenfeld, \& Gershwin, 2010; Sanchez et al., 2012) These differences among ethnic groups are due to the variation in the genetic components that is related to the ethnicity, which leads to the variation in the phenotypic expression of SLE among the individuals who have different genetic background.

Corresponding Author:-Rami Nassir.

Address:-Department of Pathology, School of Medicine, Umm Al-Qura University, Mecca, Saudi Arabia. 
For the past few years, significant progress has been done to understand the role of genetics in the pathogenesis of the disease. These studies investigated the mechanism of the disease, the occurrence, the inflammatory process and the reversible organ damage. Despite these studies, there are still significant gaps to understand the pathogenesis of the disease.(Pons-Estel et al., 2010)One of the best methods to understand the genetic roles in the development of the disease is using familial aggregation, which has been reported in many studies in SLE patients.

In Saudi Arabia, many studies emphasize the prevalence of SLE in the Saudi population. The largest study included 624 patients, 551 of these patients have Saudi genetic background. The overall of the clinical and the laboratory investigations were similar to the other populations such as the European population. However, the average age of onset was relatively lower comparing to the age of onset in different groups, which is often associated with a higherrisk of genetic role in the development of the disease.(Al Arfaj \& Khalil, 2009; Heller, Ahmed, Siddiqqi, Wallrauch, \& Bahlas, 2007; Qari, 2002)

The aim of this review is to outline the predisposing factors of SLE in the Saudi population, and to highlight the relationship between the high level of consanguinity and its role in increasing the risk of the development of SLE. In addition, it will provide an overview of the genetic diagnostic methods applied to increase the efficacy of determining the high-risk variations.

\section{Genetic Pathogenesis of Systemic Lupus Erythematosus:-}

The autoantibodies in SLE are directed against the nucleic antigens. It occurs due to abnormalities in the innate immune system, which includes the toll-like receptors beside the malfunctioning of the T-helper, IgG autoantibodies and the gene expression pattern of type- 1 interferon. All these elements would have a critical role in developing the production of the autoimmune response. Another studies emphasized the apoptosis process in the pathogenesis of the current disease. (Moulton, Lo, \& Tsokos, 2012; Shin, Lee, \& Kang, 2011; Tsokos, 2011)

Based on the findings of many studies, there is strong evidence that Lupus is a non-Mendelian complex inheritance and that there is a main role of the polygenic contribution to its pathogenesis. For the past few years, over 30 genetic loci have been identified in different ethnic backgrounds that have been associated with the risk of developing the disease.(Gateva et al., 2009; Guerra, Vyse, \& Cunninghame Graham, 2012; Harley et al., 2008; Hom et al., 2008; Moser, Kelly, Lessard, \& Harley, 2009; Ramos et al., 2011; Yang et al., 2010) Some of these genes have important roles in the immune system including T-cell regulations, B-cell differentiation and production of antibodies and dendritic cells in the antigen presentation process. Some of these genes are identified by certain Single Nucleotide Polymorphisms, SNP's that are located in certain genes. For example; the IRF5 gene, which is mainly, involved in the expression of type 1 interferon.(Graham et al., 2006; Guthridge et al., 2012)The STATA4 gene, which is an important transcription factor that has a role in the $\mathrm{TH}_{1}$, or $\mathrm{TH}_{17}$ which are associated with the autoimmunity.(Remmers et al., 2007; Shin et al., 2011) Although, some of these genes are common with autoimmunity disorders, they appear to be more specific with the Lupus especially with certain genetic variations located in these determined genes.(Ramos et al., 2011)

Also, many recent studies have shown that the high frequencies in certain genetic variations that are specific in genetic populations are associated with lupus phenotype. For example; certain genetic variations in the ETS1 and WDFY4 genes were found to be specific in the East Asian populations but not in the European populations. (Alarcon et al., 1999; Alarcon et al., 2002; Chung et al., 2009; Richman et al., 2010; Richman et al., 2012; Yang et al., 2010)

\section{Consanguinity and the development of lupus:-}

Generally, it appears that populations with high rate of consanguinity are more susceptible to genetic diseases.Consanguinity increases the overall frequency of inherited diseases including many complex phenotypic diseases such as SLE. The decrease in the heterozygositydue to the impact of the consanguineous marriages leads to increase in the uncommon genetic variations relatively to the other populations groups.(Bittles \& Black, 2010; Rudan et al., 2003)In Saudi Arabia, it has been estimated that the prevalence of consanguinity is $52 \%$ with $39.3 \%$ are in first cousin marriages.(al-Abdulkareem \& Ballal, 1998; El-Mouzan, Al-Salloum, Al-Herbish, Qurachi, \& AlOmar, 2007) Another important factor is high inbreeding coefficient due to polygamy, which is common in the Saudipopulation. In one of my published studies, using data from the Human Genome Diversity Panel (HGDP), the inbreeding coefficient was very high $\left(\mathrm{F}_{\mathrm{is}}=0.038\right)$ comparing to the other population groups. (al-Abdulkareem \& Ballal, 1998; Tian et al., 2009)Also, there are two different studies in Kuwait and Qatar thatinvestigated the genetic substructure of the population of the Arabian Peninsula. The results of these two studies support our findings that the 
Saudi population has a very small west-African contribution similar to the HGDP.(Hunter-Zinck et al., 2010; Mohammad, Xue, Evison, \& Tyler-Smith, 2009; Nassir et al., 2009) For the reasons stated above, especially the finding $\underline{s}$ in Qatar, it is extremely important to consider the genetic variation in the subgroups as it play a critical role in the development of the genetic diseases such as SLE.

\section{Genetics and Molecular Diagnosis:-}

Genome Wide Association Studies (GWAS) method has successfully identified many of the risk alleles for many complex genetic diseases.Basically, this method assesses the association between the genetic variations and the phenotype of interest such as lupus.The challenge for this method requires a large well-characterized sample for the disease, advanced genotyping technology and advanced data managing system.(Guerra et al., 2012; Iwamoto \& Niewold, 2016)

For the past few years, the success of exome-sequencing technology has achieved an important advancement. Exome sequencing is highly effective in the process of the high-throughput genetic analysis. This is accomplished by using a set of "exome capture" techniques that specifically target all the exons in the genome. This is due to the nature of the DNA and the coding regions in the human genome, which represents about $1 \%$ of the whole genome. This would allow us to approach and determine the genetic variations very easily in a coast effective approach comparing to the whole genome sequencing. (Do, Kathiresan, \& Abecasis, 2012; Manolio et al., 2009)

In complex genetic disease such as SLE, determining the genetic susceptibility is quite challenging due to the rare variants with the large genotyping effects. GWAS has successfully identified multiple susceptible genes. However, these genes do not provide any valuable insights to the pathogenesis of the disease other than the additive proportion of the hereditary risk. Therefore, it is important to consider other methods in determining the rare variant that have a significant association with the complex genetic diseases. (Fernandez et al., 2007; Iwamoto \& Niewold, 2016; Mohan \& Putterman, 2015; Williams et al., 2016)

In SLE, it is extremely important to consider rare variants for the genetic studies for many reasons. First, there areseveral family studies that have determined that there are certain deficiencies in the complement system $(\mathrm{C} 1 \mathrm{q}, \mathrm{C} 2$ and C4) that are linked to the SLE phenotype. Another study reported a mutation in the FAS ligand gene that is associated with the SLE. Also, there is another study that has reported a rare mutation in the TREX1 gene that is highly associated with the SLE development. Lately, a recent study in the Saudi population reported that there is a rare loss-of-function mutation in the DNASE1L3 gene that is associated with the recessive familial form of SLE. The later mutation was identified in several families using an autozygome analysis. (Al-Mayouf et al., 2011; Hannema et al., 1984; Lee-Kirsch et al., 2007; Meyer, Hauptmann, Tappeiner, Ochs, \& Mascart-Lemone, 1985; Rynes, 1982; Wu et al., 1996)

Therefore, it is extremely important to consider each genetic variation in a population especially for complex genetic diseases such as SLE. Also, it is crucial to consider the social behavior that has an effect in the genetic modifications such as the high rate of consanguinity in the Saudi population. Such information would help to understand the pathogenesis of the disease overall and in the Saudi population in particular. It would help to provide new methods for therapies in addition to stratifying the populations based on the genetic variations for more effective therapeutic interventions.

\section{References:-}

1. Al Arfaj, A. S., \& Khalil, N. (2009). Clinical and immunological manifestations in 624 SLE patients in Saudi Arabia. Lupus, 18(5), 465-473. doi:10.1177/0961203308100660

2. al-Abdulkareem, A. A., \& Ballal, S. G. (1998). Consanguineous marriage in an urban area of Saudi Arabia: rates and adverse health effects on the offspring. J Community Health, 23(1), 75-83.

3. Al-Mayouf, S. M., Sunker, A., Abdwani, R., Abrawi, S. A., Almurshedi, F., Alhashmi, N., . . Alkuraya, F. S. (2011). Loss-of-function variant in DNASE1L3 causes a familial form of systemic lupus erythematosus. Nat Genet, 43(12), 1186-1188. doi:10.1038/ng.975

4. Alarcon, G. S., Friedman, A. W., Straaton, K. V., Moulds, J. M., Lisse, J., Bastian, H. M., . . . Reveille, J. D. (1999). Systemic lupus erythematosus in three ethnic groups: III. A comparison of characteristics early in the natural history of the LUMINA cohort. LUpus in MInority populations: NAture vs. Nurture. Lupus, 8(3), 197209. 
5. Alarcon, G. S., McGwin, G., Jr., Petri, M., Reveille, J. D., Ramsey-Goldman, R., \& Kimberly, R. P. (2002). Baseline characteristics of a multiethnic lupus cohort: PROFILE. Lupus, 11(2), 95-101.

6. Bittles, A. H., \& Black, M. L. (2010). Evolution in health and medicine Sackler colloquium: Consanguinity, human evolution, and complex diseases. Proc Natl Acad Sci U S A, 107 Suppl 1, 1779-1786. doi:10.1073/pnas.0906079106

7. Borchers, A. T., Naguwa, S. M., Shoenfeld, Y., \& Gershwin, M. E. (2010). The geoepidemiology of systemic lupus erythematosus. Autoimmun Rev, 9(5), A277-287. doi:10.1016/j.autrev.2009.12.008

8. Cervera, R., Khamashta, M. A., Font, J., Sebastiani, G. D., Gil, A., Lavilla, P., . . Hughes, G. R. (1999). Morbidity and mortality in systemic lupus erythematosus during a 5-year period. A multicenter prospective study of 1,000 patients. European Working Party on Systemic Lupus Erythematosus. Medicine (Baltimore), $78(3), 167-175$.

9. Chung, S. A., Tian, C., Taylor, K. E., Lee, A. T., Ortmann, W. A., Hom, G., . . Criswell, L. A. (2009). European population substructure is associated with mucocutaneous manifestations and autoantibody production in systemic lupus erythematosus. Arthritis Rheum, 60(8), 2448-2456. doi:10.1002/art.24707

10. Do, R., Kathiresan, S., \& Abecasis, G. R. (2012). Exome sequencing and complex disease: practical aspects of rare variant association studies. Hum Mol Genet, 21(R1), R1-9. doi:10.1093/hmg/dds387

11. El-Mouzan, M. I., Al-Salloum, A. A., Al-Herbish, A. S., Qurachi, M. M., \& Al-Omar, A. A. (2007). Regional variations in the prevalence of consanguinity in Saudi Arabia. Saudi Med J, 28(12), 1881-1884.

12. Fernandez, M., Alarcon, G. S., Calvo-Alen, J., Andrade, R., McGwin, G., Jr., Vila, L. M., \& Reveille, J. D. (2007). A multiethnic, multicenter cohort of patients with systemic lupus erythematosus (SLE) as a model for the study of ethnic disparities in SLE. Arthritis Rheum, 57(4), 576-584. doi:10.1002/art.22672

13. Fessel, W. J. (1974). Systemic lupus erythematosus in the community. Incidence, prevalence, outcome, and first symptoms; the high prevalence in black women. Arch Intern Med, 134(6), 1027-1035.

14. Gateva, V., Sandling, J. K., Hom, G., Taylor, K. E., Chung, S. A., Sun, X., . . Graham, R. R. (2009). A largescale replication study identifies TNIP1, PRDM1, JAZF1, UHRF1BP1 and IL10 as risk loci for systemic lupus erythematosus. Nat Genet, 41(11), 1228-1233. doi:10.1038/ng.468

15. Graham, R. R., Kozyrev, S. V., Baechler, E. C., Reddy, M. V., Plenge, R. M., Bauer, J. W., . . AlarconRiquelme, M. E. (2006). A common haplotype of interferon regulatory factor 5 (IRF5) regulates splicing and expression and is associated with increased risk of systemic lupus erythematosus. Nat Genet, 38(5), 550-555. doi:10.1038/ng 1782

16. Guerra, S. G., Vyse, T. J., \& Cunninghame Graham, D. S. (2012). The genetics of lupus: a functional perspective. Arthritis Res Ther, 14(3), 211. doi:10.1186/ar3844

17. Guthridge, J. M., Clark, D. N., Templeton, A., Dominguez, N., Lu, R., Vidal, G. S., . . Poole, B. D. (2012). Effects of IRF5 lupus risk haplotype on pathways predicted to influence B cell functions. J Biomed Biotechnol, 2012, 594056. doi:10.1155/2012/594056

18. Hannema, A. J., Kluin-Nelemans, J. C., Hack, C. E., Eerenberg-Belmer, A. J., Mallee, C., \& van Helden, H. P. (1984). SLE like syndrome and functional deficiency of C1q in members of a large family. Clin Exp Immunol, 55(1), 106-114.

19. Harley, J. B., Alarcon-Riquelme, M. E., Criswell, L. A., Jacob, C. O., Kimberly, R. P., Moser, K. L., .. Kelly, J. A. (2008). Genome-wide association scan in women with systemic lupus erythematosus identifies susceptibility variants in ITGAM, PXK, KIAA1542 and other loci. Nat Genet, 40(2), 204-210. doi:10.1038/ng.81

20. Heller, T., Ahmed, M., Siddiqqi, A., Wallrauch, C., \& Bahlas, S. (2007). Systemic lupus erythematosus in Saudi Arabia: morbidity and mortality in a multiethnic population. Lupus, 16(11), 908-914. doi:10.1177/0961203307081112

21. Hersh, A. O., Alarcon, G. S., Bonetto, C., Pernus, Y. B., Kucuku, M., Santuccio, C., . . Bonhoeffer, J. (2016). Systemic Lupus Erythematosus: Case definition and guidelines for data collection, analysis, and presentation of immunization safety data. Vaccine, 34(51), 6572-6581. doi:10.1016/j.vaccine.2016.09.031

22. Hom, G., Graham, R. R., Modrek, B., Taylor, K. E., Ortmann, W., Garnier, S., . . . Behrens, T. W. (2008). Association of systemic lupus erythematosus with C8orf13-BLK and ITGAM-ITGAX. N Engl J Med, 358(9), 900-909. doi:10.1056/NEJMoa0707865

23. Hunter-Zinck, H., Musharoff, S., Salit, J., Al-Ali, K. A., Chouchane, L., Gohar, A., . . Clark, A. G. (2010). Population genetic structure of the people of Qatar. Am J Hum Genet, 87(1), 17-25. doi:10.1016/j.ajhg.2010.05.018

24. Iwamoto, T., \& Niewold, T. B. (2016). Genetics of human lupus nephritis. Clin Immunol. doi:10.1016/j.clim.2016.09.012 
25. Lee-Kirsch, M. A., Gong, M., Chowdhury, D., Senenko, L., Engel, K., Lee, Y. A., . . Hubner, N. (2007). Mutations in the gene encoding the 3'-5' DNA exonuclease TREX1 are associated with systemic lupus erythematosus. Nat Genet, 39(9), 1065-1067. doi:10.1038/ng2091

26. Lopez, P., Mozo, L., Gutierrez, C., \& Suarez, A. (2003). Epidemiology of systemic lupus erythematosus in a northern Spanish population: gender and age influence on immunological features. Lupus, 12(11), 860-865.

27. Manolio, T. A., Collins, F. S., Cox, N. J., Goldstein, D. B., Hindorff, L. A., Hunter, D. J., . . Visscher, P. M. (2009). Finding the missing heritability of complex diseases. Nature, 461(7265), 747-753. doi:10.1038/nature08494

28. Meyer, O., Hauptmann, G., Tappeiner, G., Ochs, H. D., \& Mascart-Lemone, F. (1985). Genetic deficiency of C4, C2 or C1q and lupus syndromes. Association with anti-Ro (SS-A) antibodies. Clin Exp Immunol, 62(3), 678-684.

29. Mohammad, T., Xue, Y., Evison, M., \& Tyler-Smith, C. (2009). Genetic structure of nomadic Bedouin from Kuwait. Heredity (Edinb), 103(5), 425-433. doi:10.1038/hdy.2009.72

30. Mohan, C., \& Putterman, C. (2015). Genetics and pathogenesis of systemic lupus erythematosus and lupus nephritis. Nat Rev Nephrol, 11(6), 329-341. doi:10.1038/nrneph.2015.33

31. Moser, K. L., Kelly, J. A., Lessard, C. J., \& Harley, J. B. (2009). Recent insights into the genetic basis of systemic lupus erythematosus. Genes Immun, 10(5), 373-379. doi:10.1038/gene.2009.39

32. Moulton, V. R., Lo, M. S., \& Tsokos, G. C. (2012). Methods and protocols to study T cell signaling abnormalities in human systemic lupus erythematosus. Methods Mol Biol, 900, 25-60. doi:10.1007/978-160761-720-4_3

33. Nassir, R., Kosoy, R., Tian, C., White, P. A., Butler, L. M., Silva, G., . . . Seldin, M. F. (2009). An ancestry informative marker set for determining continental origin: validation and extension using human genome diversity panels. BMC Genet, 10, 39. doi:10.1186/1471-2156-10-39

34. O'Neill, S., \& Cervera, R. (2010). Systemic lupus erythematosus. Best Pract Res Clin Rheumatol, 24(6), 841855. doi:10.1016/j.berh.2010.10.006

35. Pons-Estel, G. J., Alarcon, G. S., Scofield, L., Reinlib, L., \& Cooper, G. S. (2010). Understanding the epidemiology and progression of systemic lupus erythematosus. Semin Arthritis Rheum, 39(4), 257-268. doi:10.1016/j.semarthrit.2008.10.007

36. Qari, F. A. (2002). Clinical pattern of systemic lupus erythematosus in Western Saudi Arabia. Saudi Med J, 23(10), 1247-1250.

37. Ramos, P. S., Criswell, L. A., Moser, K. L., Comeau, M. E., Williams, A. H., Pajewski, N. M., . . Langefeld, C. D. (2011). A comprehensive analysis of shared loci between systemic lupus erythematosus (SLE) and sixteen autoimmune diseases reveals limited genetic overlap. PLoS Genet, 7(12), e1002406. doi:10.1371/journal.pgen.1002406

38. Remmers, E. F., Plenge, R. M., Lee, A. T., Graham, R. R., Hom, G., Behrens, T. W., . . Gregersen, P. K. (2007). STAT4 and the risk of rheumatoid arthritis and systemic lupus erythematosus. N Engl J Med, 357(10), 977-986. doi:10.1056/NEJMoa073003

39. Richman, I. B., Chung, S. A., Taylor, K. E., Kosoy, R., Tian, C., Ortmann, W. A., . . . Criswell, L. A. (2010). European population substructure correlates with systemic lupus erythematosus endophenotypes in North Americans of European descent. Genes Immun, 11(6), 515-521. doi:10.1038/gene.2009.80

40. Richman, I. B., Taylor, K. E., Chung, S. A., Trupin, L., Petri, M., Yelin, E., . . . Criswell, L. A. (2012). European genetic ancestry is associated with a decreased risk of lupus nephritis. Arthritis Rheum, 64(10), 33743382. doi:10.1002/art.34567

41. Rudan, I., Rudan, D., Campbell, H., Carothers, A., Wright, A., Smolej-Narancic, N., . . . Rudan, P. (2003). Inbreeding and risk of late onset complex disease. J Med Genet, 40(12), 925-932.

42. Rynes, R. I. (1982). Inherited complement deficiency states and SLE. Clin Rheum Dis, 8(1), 29-47.

43. Sanchez, E., Rasmussen, A., Riba, L., Acevedo-Vasquez, E., Kelly, J. A., Langefeld, C. D., . . . AlarconRiquelme, M. E. (2012). Impact of genetic ancestry and sociodemographic status on the clinical expression of systemic lupus erythematosus in American Indian-European populations. Arthritis Rheum, 64(11), 3687-3694. doi:10.1002/art.34650

44. Shin, M. S., Lee, N., \& Kang, I. (2011). Effector T-cell subsets in systemic lupus erythematosus: update focusing on Th17 cells. Curr Opin Rheumatol, 23(5), 444-448. doi:10.1097/BOR.0b013e328349a255

45. Smith, P. P., \& Gordon, C. (2010). Systemic lupus erythematosus: clinical presentations. Autoimmun Rev, 10(1), 43-45. doi:10.1016/j.autrev.2010.08.016 
46. Tian, C., Kosoy, R., Nassir, R., Lee, A., Villoslada, P., Klareskog, L., . . . Seldin, M. F. (2009). European population genetic substructure: further definition of ancestry informative markers for distinguishing among diverse European ethnic groups. Mol Med, 15(11-12), 371-383. doi:10.2119/molmed.2009.00094

47. Tsokos, G. C. (2011). Systemic lupus erythematosus. $N$ Engl J Med, 365(22), $2110-2121$. doi:10.1056/NEJMra1100359

48. Williams, E. M., Bruner, L., Adkins, A., Vrana, C., Logan, A., Kamen, D., \& Oates, J. C. (2016). I too, am America: a review of research on systemic lupus erythematosus in African-Americans. Lupus Sci Med, 3(1), e000144. doi:10.1136/lupus-2015-000144

49. Wu, J., Wilson, J., He, J., Xiang, L., Schur, P. H., \& Mountz, J. D. (1996). Fas ligand mutation in a patient with systemic lupus erythematosus and lymphoproliferative disease. J Clin Invest, 98(5), 1107-1113. doi:10.1172/jci118892

50. Yang, W., Shen, N., Ye, D. Q., Liu, Q., Zhang, Y., Qian, X. X., . . . Lau, Y. L. (2010). Genome-wide association study in Asian populations identifies variants in ETS1 and WDFY4 associated with systemic lupus erythematosus. PLoS Genet, 6(2), e1000841. doi:10.1371/journal.pgen.1000841 